\title{
S5.5
}

\section{HEPATITIS C VIRUS AND HUMAN LYMPHOMAS}

\section{Luppi M., Barozzi P., Torelli G.}

Dipartimento di Oncologia ed Ematologia.

Università di Modena e Reggio Emilia. Modena.

$\mathrm{HCV}$ infection is associated with certain B cell non Hodgkin lymphoma (NHL) types (marginal zone and diffuse large cell lymphoma) in geographical areas with HCV endemicity, like Italy and Japan, where $\mathrm{HCV}$ prevalence rates range from 20 to $40 \%$. The putative mechanisms exploited by HCV to induce B cell lymphoproliferation are new and differ from the classical mechanisms of herpesviral induced lymphomagenesis, including the induction of a "mutator phenotype" in B cells (high mutation frequency of immunoglobulin, BCL-6, p53 and beta-catenin genes), and the initial and direct activation, by the HCV E2 envelope glycoprotein, of B cells which in turn give rise to frank lymphoma. The regression of some HCVrelated lymphoma types following antiviral therapy with interpheron alpha and ribavirin probably represents the strongest argument in favour of an etiologic link between HCV infection and human lymphomas. In most of the cases, clinical response correlated well with the loss of detectable HCV RNA, the occurrence of clinical relapse being associated with the reappearance of detectable viral load in the peripheral blood, indicating an important role of viral molecular testing in the clinical management of these patients 